\title{
AÇÃO ALELOPATICA DE ALGUNS EXTRATOS DE PLANTAS DANINHAS NA GERMINAÇAO DO ARROZ (Oryza sativa L. CV. IAC - 165)*
}

\author{
Paulo R.C. Castro**

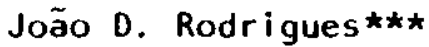

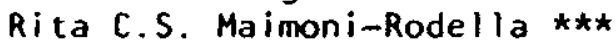

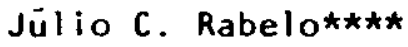 \\ Renato F.A. Veigatt*t \\ Giuseppina P.P. Lima*t**

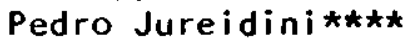

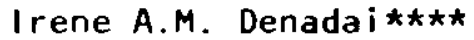

\section{RESUMO}

0 efeito do extrato aquoso de três plan tas daninhas, Cynodon dactylon (L.) Pers., Cyperus rotunilus $\mathrm{L}$. e Sorghum halepense (L.) Pers. sobre a germinação e o crescimento de plântulas de arroz (Oryza sa

* Entregue para publicação en 28/12/84.

** Departamento de Botànica da E.S.A. "Luiz de Queiroz"', USP.

*** Departamento de Botânica. IBBMA, UNESP - Campus de Botucatu.

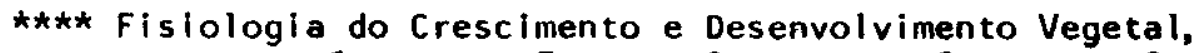
Curso de Pós-Graduação em Ciências Biológicas-Botânica, UNESP - Campus de Botucatu. 
lina L. CV. (AC-165) foi estudado, com a finalidade de investigar a sensibilidade do arroz aos efeitos alelopáticos dessas plantas. Foram utilizados, na preparaçäo dos extratos, raizes de liynidind drilylon, tubërculos de cyperus milurth: e rizomas de "iorghwm halequense, os quais foram homoneizados en solução aquosa, submetidos a filtração e centri fugação. 0 sobrenadante foi aplicado no substrato de germinação das sementes, verificando-se, aos sete dias apōs a se meadura, que apenas os extratos de $c y^{-}$ nulkm lix.tylon e Sorghum halepents afetaram a porcentagem de germinação das sementes de arroz. Entretanto, o crescimento da radícula e da parte aérea das plântulas foi prejudicado pelos três extratos testados, sendo o efeito mais drástico causado pelo extrato de cyysemitituriths.

INTRODUÇÃO

Em anos recentes têm-se notado um expressivo incremento no número de pesquisas relativas a alelopatia, particularmente no que se refere aos efeitos da alelopatia na agricultura, silvicultura, fitopatologia, padröes vegetacionais, sucessão de algas e sucessão em campos abandonados. Tais pesquisas têm contribuido muito para a melhor compreensão de inümeros fenōmenos de interação entre plantas, e grande parte delas encontra-se criticamente comentada no trabalho de revisão realizado por RICE (1979), onde se podem encontrar värias referências sobre revisóes similares realizadas por outros autores. 
De acordo com RICE (1979) o termo alelopatia fol primeiramente ut llizado por MOLISCH (1937) para designar qualquer interaçào bioquimica eníre todos os tipos de plantas, inclusive inicrorganismos, sendo que neste termo ficariam englobadas interações bioquímicas recíprocas, be néficas e prejudiciais. Outros autores utilizam o termo alelopatia para expressar apenas as interaçoes bioquímicas prejudiciais de uma planta sobre a outra, como por exemplo DORST \& DOLL (1980) e MACFARLANE et alii (1982). Entretanto, RICE (1979) recomenda o emprego do termo con forme a definição prévia de MOLISCH (1937).

Hä grande interesse no estudo da alelopatia, especialmente porque esse tipo de interação é complexa e fre quentemente confundida com competição (MACFARLANE et alii, 1982). Desde que haja dificuldade para distinção entre competição e alelopatia, deve-se usar a palavra "interferência" para expressar uma redução de crescimento cuja causa näo pode ser precisada (Muller, 1969, cita do por RICE, 1979). Desta forma, reveste-se de maior im portância a investigação sobre a ocorrência de substâñ cias de efeito alelopático em plantas daninhas, cuja ação prejudicial, sobre as culturas, quase sempre é referida em termos de competição.

Cynodun dactiton (L.) Pers, è relatada como planta daninha em áreas agricolas de regiōes tropicais e subtro picais, sendo encontrada em todas as classes de solos (BEHRENDT \& HANF, 1979). Segundo. LORENZI (1982), ocorre em 80 países, sendo encontrada no Bras 1 l em lavouras anuais e perenes, bordas de estradas e ierrenos baldios. o extrato aquoso de suas folhas inibiu a germinação e o crescimento da radícula de sementes de alface (Chou $\varepsilon$ Young, 1975, citados por RICE, 1979), enquanto o extrato aquoso de seu sistema radicular prejudicou a germinação e o crescimento do hipocótilo em plántulas de tomateiro (CASTRO et alii, 1983).

A tiririca (Cyperus rotundus, L.) faz parte do con junto de plantas daninhas mais prejudiciais para as cul= 
turas tropicais e subtropicais (BEHRENDT E HANF, 1979). estando .largamente distibuida no Brasil, onde pode ser encontrada em todos tipos de solos, climas e culturas, exceto em lavouras de arroz inundado (LORENZI, 1982). Plantas de Cyperus rolundus incorporadas ao solo inibiram a germinação de sementes de tomateiro, pimenta, sorgo e Celosia argentea, em condiçöes de casa de vegetação (MOHAMED-SALEEM \& FAWUSI, 1983), evidenciando um efeito a le lopātico significativo. LORENZI (1982) ainda menciona que, além de sua grande capacidade competitiva, Cypomis rotundus exerce efeito alelopático, inibindo a brota ção de culturas, principalmente da cana-de-açúcar. CASTRO et alii (1983) observarain que o extrato de Cyperus rotundus inibiu completamente a germinação de sementes de tomateiro.

Em regiöes de clima quente, Sorghum halepensc (L.) Pers. é planta daninha bastante importante nas culturas de soja, algodão e cana-de-açūcar (BEHRENDT \& HANF, 1979). No Brasil, sua ärea de infestação vem aumentando acentua damente, sendo no momento mais frequente ao longo de rodovias, e em äreas de cana-de-açūcar (LORENZI, 1982). 0 extrato de "iorghum halepense inibiu completamente a germinação de sementes de tomateiro (CASTRO et alii, 1983).

Una vez que a ação de extratos aquosos dessas trés plantas daninhas sobre uma Dicotiledōnea já è conhecida, realizuu-se o presente trabalho com o objetivo de estudar a ação dos referidos extratos sobre a germinação e o crescimento das plântulas de uma Monocotiledōnea, utilizando-se como planta indicadora o arroz (Orysa sativa L. CV. $(A C-165)$.

MATERIAIS E METODOS

As plantas utilizadas, no presente ensaio, foram 
obtidas ell äreas experimentais da E.S.A. "Luiz de Queiroz", USP, Piracicaba (SP), sendo coletadas no dia anterior ao preparo dos extratos e trazidas ao Departamento de Botânica da UNESP, Botucatu (SP), onde os ensaios for ramrealizados. Foram coletadas raizes de cynodon dacty= Ion (L.) Pers. (grama-sêda), tubérculos de Cyperus rotun dus L. (tiririca) e rizomas de Sorghwm halepense (L.) Pers. (capim-massambarā), sendo as coletas realizadas em agosto e setembro de 1984 .

O sistema radicular de Cynodon dactylon foi lavado, seco ao ar e pesado, adicionando-se em seguida água deio nizada na proporção de $4: 1$, homogeneizando-se, posteriór mente, esse material. Procedeu-se da mesma forma com ós tubérculos de Cyperus rotundus, adicionando-se ägua de io nizada na proporção de 3:1, e igualmente com os rizomas de Sorghum halepense, juntando-se água deionizada na pro porção de $4: 1$.

Em seguida, procedeu-se à trituração de cada material separadamente, ut ilizando-se liquidificador e homogeinizador Virtis 45, sendo obtidos os extratos aquosos, que foram filtrados em funil com papel de filtro Watman n? I. Os extratos filtrados foram submetidos à centrifu gação durante 10 minutos a $3000 \mathrm{rpm}$, em centrífuga Sorvall SS-4. Os sobrenadantes assim obtidos foram mantidos em geladeira a $5^{\circ} \mathrm{C}$, até o momento de sua utilização.

Com a finalidade de verificar o efeito dos extratos obtidos na germinação de sementes de arroz (Oryza sa tiva L. CV. (AC-165). adicionaram-se $10 \mathrm{ml}$ de extrato por placa de Petri previamente forrada com algodäo e papel de filtro, contendo tambëm 10 sementes de arroz, sendo assim preparadas 10 repetições para cada tlpo de extrato. Realizou-se o controle em placas de Petri preparadas de modo idêntico, recebendo entretanto $10 \mathrm{ml}$ de àgua deloni zada ao Invës de extrato. Todas as placas foram mantidas em germinador a temperatura de $20-25^{\circ} \mathrm{C}$ e 12 horas de claro/12 horas de escuro, durante 7 dias, determinando-se, em seguida, a porcentagem de germinaçäo e os compr 1 
mentos da radícula e dos coleöptiles ou das folhas primā rlas das plântulas, os quals serão aqui referidos como parte aérea das plântulas para maior facilidade de redação.

\section{RESULTADOS E DISCUSSAOO}

0s resultados encontram-se relacionados na Tabela 1 e nas Figuras 1,2 e 3 . Pode-se verificar que o extra to aquoso de Cynodon dactylon reduziu a porcentagem de germinação das sementes de arroz, observando-se também que houve um efeito inibidor mais pronunciado no crescimento da parte aérea das plántulas que na radicula (Tabe la 1 , Figura 1). De acordo com Chou $\&$ Young (1975), ci= tados por RICE (1979), o extrato aquoso de follhas de $(y-$ nodon dactylon inibiu a germinaçāo e o crescimento da ra dicula de sementes de alface. Para o arroz, o efeito foi, portanto, um tanto diverso, pois houve inibiçãomais acentuada no crescimento da parte aérea das plàntulas.

Conforme pode-se observar na Tabela I e na Figura 2, o extrato aquoso de c'ypems rutundus não apresentou efei to sobre a porcentagem de germinação de sementes de arroz. Entretanto, as sementes tratadas com o extrato não apresentaram emissão da radicula, sendo que apenas o coleoptile emergiu, evidenciando o efeito altamente inibitörio do extrato de cyperus rotundus sobre o crescimen to das plântulas de arroz. Assim, embora tenham germina do, as sementes tratadas com extrato de Cyperus rotundis apresentaram o crescimento das plântulas bastante prejudicado. Esta resposta difere daquela obtida por CASTRO et alli (1983) para sementes de tomateiro, onde o mesmo tipo de extrato Iniblu totalmente a germinação. 


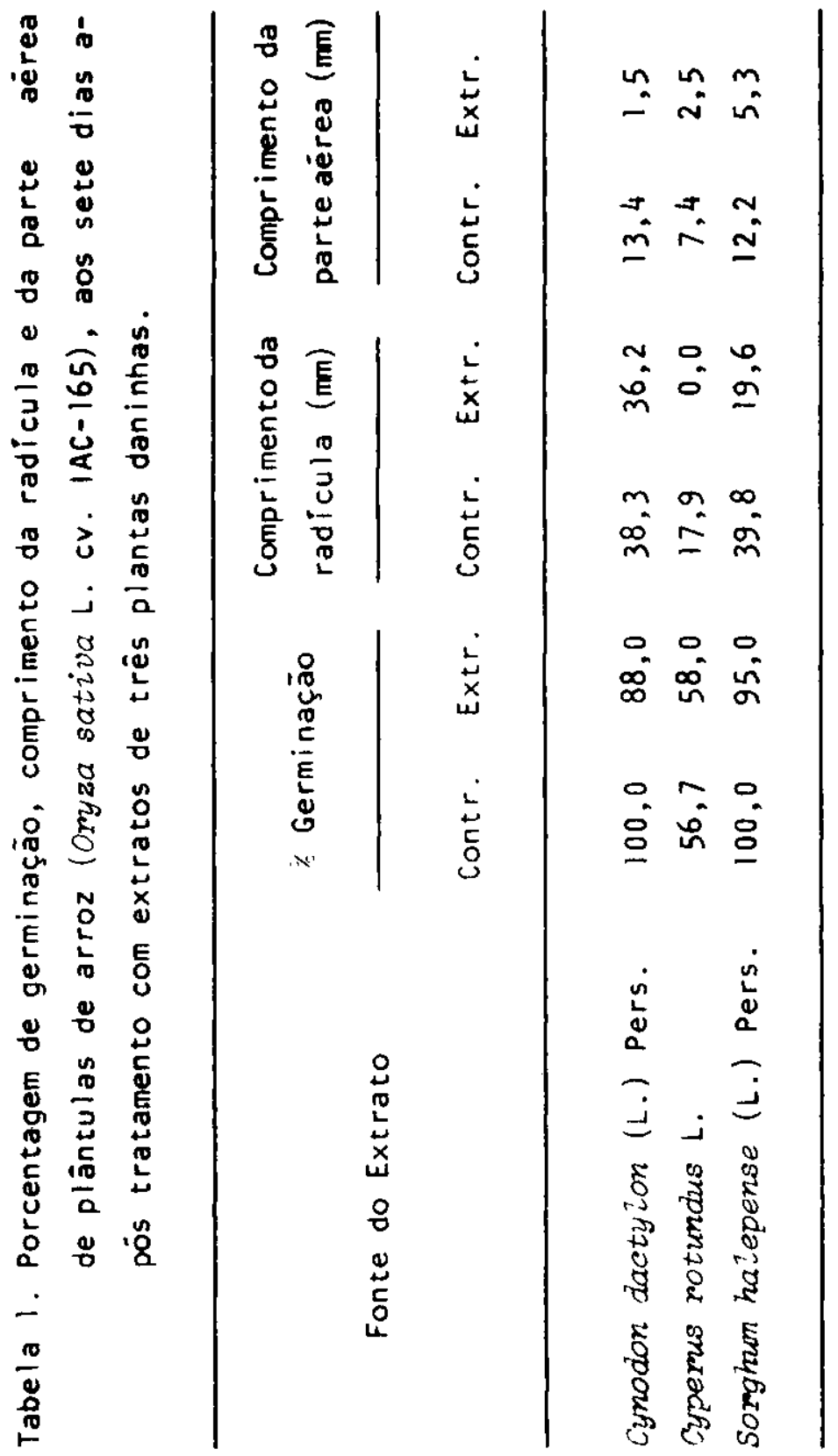




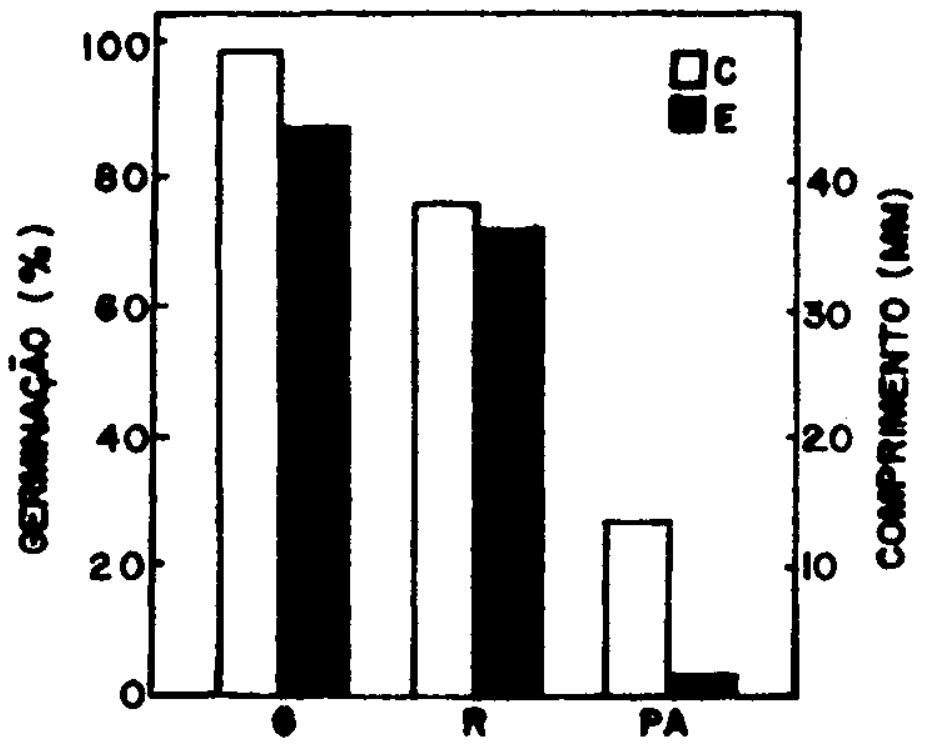

Figura 1 - Efeito do estrato de plantas inteiras de Cynodon dactylon (L) Pers. sobre a porcen tagem de germinação e comprimentos da rādicula e da parte aérea de plântulas de arroz, aos 7 di as apös a semeadura. G:ger minação; $R$ : radícula; PA: parte aérea; $C$ : controle; $E$ : extrato. 


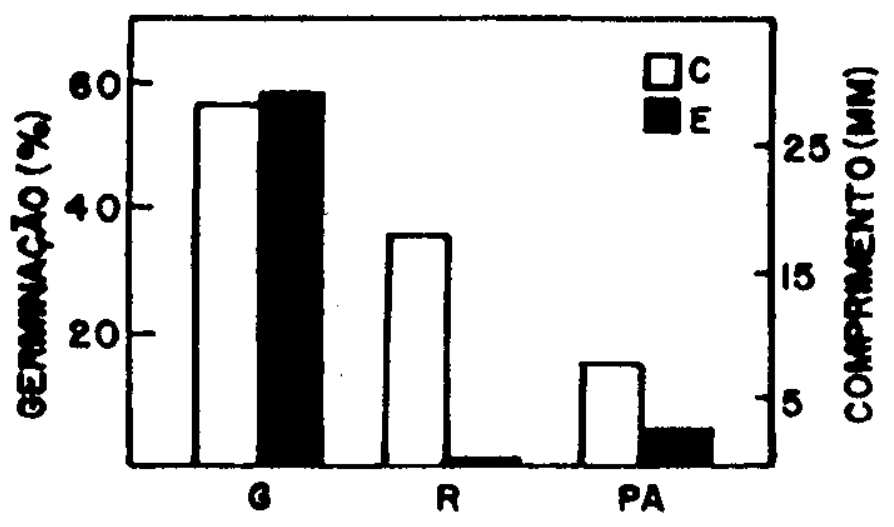

Figura 2 - Efeito do extrato de tubërculos de Cyperus rotundus, L sobre a porcentagem de germinação e comprimentos da radícula e da parte aé rea de plántulas de arroz, aos 7 dias após a semeadura. G: germinação; $R$ radícula; $P A$ : parte aérea; C: controle; E: extrato. 


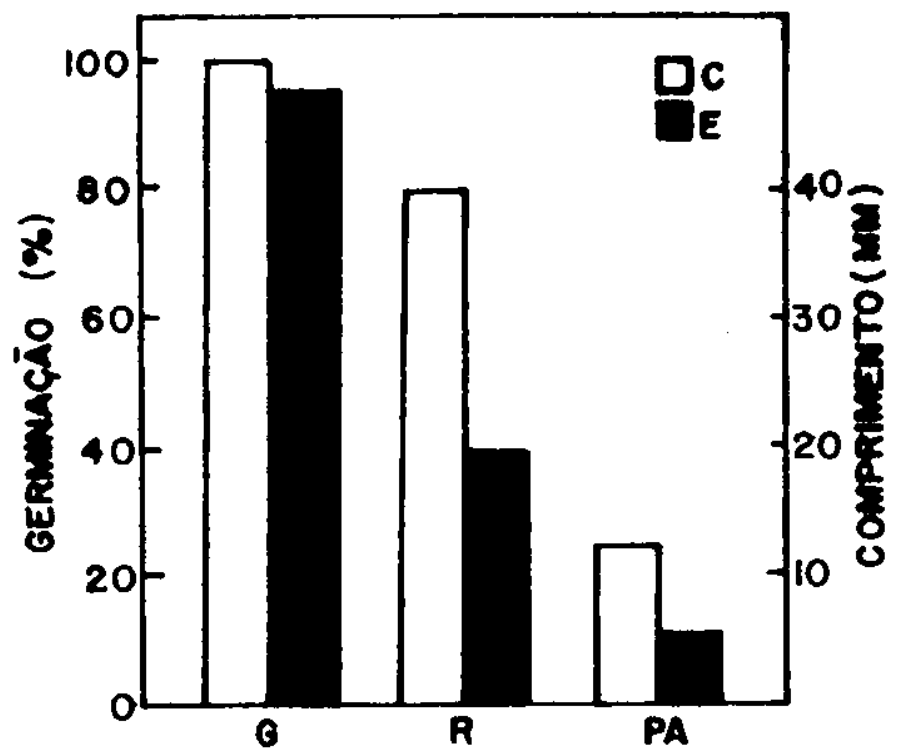

Figura 3 - Efeito do extrato de rizomas de Sorghum halepense (L.) Pers. sobre a porcentagem de germinação e comprimentos da radícula e da parte aérea de plántulas de arroz, aos 7 di as apōs a semeadura. G: germinação; $R$ : rạ dícula; PA: parte aẻrea; $C$ : controle; $E$ : $\underline{e} \underline{\underline{x}}$ trato. 
Na Tabela 1 e figura 3, encontram-se relacionado os dados obtidos com o emprego do extrato aquoso de Sor ghum haleprnse. Pode-se considerar que a inibição na germinaçäo causada pelo referldo extrato fol mínima. No entanto, o crescimento das piantulas de arroz fol bastan te inibido pelo extrato, evidenclando certa ação alelop tica. Segundo Overland (1966), ci tado por RICE (1979), Sorghum vulyare apresenta efeito alelopático, tendo sido utilizado frequentemente para suprimir o crescimento de plantas daninhas.

Os efeitos inibidores dos très extratos testados sāo evidentes. Entretanto, o poder inibitório de extratos de plantas sobre outras plantas, detectado através de ensaios de laboratörio, não indica necessarlamente a ocorrência de efeitos alelopáticos sob condições de campo. Segundo RICE (1979), uma parte essencial da alelopa tia é o movimento do agente alelopático potencial no meīo ambiente. Assim, o material exsudado e lixiviado das plan tas daninhas e o solo local deveriam ser testados contrá as culturas que se pretende instalar na ärea. Estas con sideraçōes evidenciam, portanto, a necessidade de mais estudos sobre o assunto, particularmente em regiöes tropicais onde há escassez acentuada desse tipo de dados (MOHAMED-SALEEN \& FAWUSI, 1983).

\section{CONCLUSOES}

Os resultados obtidos permitem inferir as seguintes conclusōes:

- Extrato aquoso do sistema radicular de Cynodon dactylon reduziu a germinação e inibiu o crescimento da parte aērea de Oryza sativa;

- Extrato dos tubërculos de Cyperus rotundus ini. 
biu totalmente o desenvolvimento da radicula e diminuiu o cresci.mento da parte aérea da planta teste;

- Extrato dos rizomas de Sorghum halepense reduziu - crescimento da radícula e da parte aérea de arroz.

SUMMARY

ALLELOPATHIC ACTION OF SOME WEED EXTRACTS ON RICE GERMINATION

The present study was carried out to evaluate the possible allelopathic effects of Cynodon dactylon, cyperus rotundus and Sorghwm halepense on seed germination of Oryza sativiy cv. IAC-165. Extracts from roots of cynodon dactylion and iorghum halepense and from tubers of Cyperus rotundus were used to evaluate the effects on rice seed germination. Aqueous solution of these organs, obtained by homogenization, filtration and centrifugation, were introduced on Petri dishes containing rice seeds. The evaluation of germination and initial growth showed a strong negative effect of all three weeds studied.

LITERATURA CITADA

BEHRENDT; S.; HANF, M., 1979. Malezas gramineas en los cultivos agrícolas. BASF, Barcelona, $159 \mathrm{p}$.

CASTRO, P.R.C.; RODRIGUES, J.D.; MORAES, M.A.; CARVALHO, V.L.M., 1983. Efeitos alelopáticos de alguns extra- 
tos vegetais na germinação do tomatelro (Lyorpersicon esculentum Mill. cv. Santa Cruz). Planta Daninha 6 (2) : 79-85.

DORST, D.C.; DOLL, J.D., 1980. Allelopathy: some weeds use it against crops. Crops and Soil Mag. 3:5-6.

LORENZI, H., 1982. Plantas daninhas do Brasil: terrestres, aquáticas, parasitas, tōxicas e medicinais. No va Odessa, $425 \mathrm{p}$.

MACFARLANE, M. J.; SCOTT, D.; JARVIS, P., 1982. Allelopathic effects of white clover 1. Germination and chemical bioassay. New Zel. J. Agric. Res. 25: :503-510.

MOHAMED-SALEEM, M.A.; FAWUSI, M.0.A., 1983. A note on the effects of tropical weed decomposition on seed germination and seedling growth of some agricultural crops. Agric. Ecosystems Environ. 10(4):347-352.

RICE, E.L., 1979. Allelopathy - an update. Bot. Rev. 45(1):15-109. 